\title{
A Move Towards A More Sustained Competitive Institution: Using theories of Structure and Change
}

\author{
Cerease Nevins-Bennett \\ School of Business and Entrepreneural Studies \\ Excelsior Community College \\ cereasenevins@hotmail.co.uk
}

\begin{abstract}
Many technical and vocational colleges have gone through a number of transformations in its structure and functions as a result of increased competition, increased Government pressures to stay within its mandate as technical vocational institutions, and to become more sustainable. The Porter's Five Forces will be used to determine the extent of the institutions level of competitiveness and sustained competitive advantage. Results of the study show that the threats to new entrants, threats to substitute products, suppliers bargaining power, and buyers bargaining power were all statistically significant predictors of the level of competitiveness among the technical and vocational colleges. However, the $\log$ of the odds of the institutions maintaining sustained competitive advantage was negatively related to threats to suppliers bargaining power, as these technical and vocational colleges were .389 times less likely to maintain sustained competitive advantage, being $\mathbf{9 5 \%}$ confident that the population value of the odds ratio lies between [CI]0.157 and 1.009 .
\end{abstract}

Keywords: Miles and Snow typology, Porter's Five Forces, change theories, theories of organizational structure, and Sustainable competitive advantage.

\section{INTRODUCTION}

It is important to understand the organizational structure and design of an entity and the environment in which it operates so as to determine whether or not it is operating efficiently and is in need of change or reengineering. In a competitive environment, technical vocational colleges have to be restructuring to adapt to changes caused by globalization, competition, and meeting the demands of its customers. An organization of this nature is complex, and has to respond and make decisions as it relates to the various contingencies that exist. A switch to a semi- virtual institution is often appropriate where colleges wish to differentiate themselves, become early adopters according to Miles and Snow Typology as well as to become a low cost defender.

Virtual classrooms are the new and emerging trends in this technological and informational era and many colleges and universities have provided their busy customers with an educational package through distance learning and e-learning. To move to this stage, the technical and vocational colleges in Jamaica have to make planned and radical changes to be successful and to change its structure. This of course will require tremendous amount of funding and training at all levels; but before that can be achieved, the technical and vocational colleges need to assess their levels of competition and aim to maintain sustained competitive advantage. 
This article is two-fold as it begin by looking at the structural and design problems existing at two Technical and vocational colleges through the lens of various structure and change theories in management. It then uses the Porter's Five Forces to determine the level of competition and the odds or likelihood of these institutions maintaining sustained competitive advantage in moving forward in its mandate to providing quality education in the Caribbean.

\section{BACKGROUND OF THE COLLEGES: A THEORETICAL APPLICATION Structure and Design of the institution}

The Technical and vocational colleges in Jamaica are professional bureaucratic structures as presented in Mintzberg's five organizational archetypes. According to Schmidt (2006) the professional bureaucratic configuration uses coordination by standardization of skills, and is in effect the only organizational structure that allows standardization and decentralization to coexist (Schmidt, 2006). Schmidt (2006) stated that:

"The professional bureaucratic structure contains a large number of knowledge workers, and is complex in nature with many rules and procedures to follow. Because of its professional workers, the operating core becomes the key organizational part, but it is usually supported by a very elaborate support staff. The middle line is very short, and is often populated by professionals whom also participate in the operating core. The technostructure is very small and without importance. The Professional Bureaucracy is highly decentralized in both dimensions, but because the support structure is so large, a parallel machine like configuration sometimes emerges in this part"

This statement above presented by Schmidt is often seen in technical and vocational colleges where ten to fifteen percent of the academic staff only possesses a bachelor's degree and holds senior lecturer positions. For the minority of workers, their mode of delivery and content are dated as no further upgrade of qualification has taken place; to add to this, more than fifty percent of the Administrative staff only possesses ordinary levels qualifications. The operating core (Lecturers) according to Schmidt should be supported by the support staff (administrative staff) but this is not always the case in our colleges. Administrative staff are sometimes reluctant to provide the needed services such as photocopying and printing to facilitate the lecturers, a simple task such as to roll off exam scripts and coordinate invigilators are daunting tasks within the colleges as the Administrative staff have proven to be difficult sets of workers and are not working collaboratively with the academic staff unless these staff members have seniority positions.

The main variables in organizational design are related to the contingencies of the environment, size and technology (Clegg, 2009). It is argued that the more certain and predictable the environment in which organizations operate, the greater the probability of bureaucratic structures occurring (Clegg, 2009). The structure and organizational environment and design of the technical and vocational colleges are further supported in Burns and Stalker's contingency theory where it is operating as an organic structure. All the Colleges' organizational structure works best in a dynamic and uncertain environment where rapid communication and information sharing is necessary and departments and functional areas are tightly integrated; tasks are differentiated so as to allow the lecturers to respond quickly to changing situations or contingencies. Complex decision making is made at all levels of the hierarchy as the academic, administrative and ancillary staff are given some amount of autonomy to make decisions without having to consult the Principal, Head of Department and 
Deans. According to Burns and Stalker, when tasks changes rapidly, it is unfeasible to institute standardization and formalization procedures, instead tasks should be mutually adjusted, which is evident at the colleges.

In terms of organizational design and mode of operation, Burns and Stalker's contingency perspective will enable the Principals to examine various situations within their own institutions, and determine the cause of problems experiences before a new procedure or program is implemented. However, the drawback to this theory is that an awareness of all possible solutions to the problem must be made in order for the Principals, Heads of School and Deans to be able to arrive at a correct solution. This theory thus supports Mintzberg's professional bureaucratic approach that is evident at the colleges.

\section{Theory of Organizational Design}

Lawrence and Lorsch's theory of organizational design and operation was used to analyze the organizational design and operations of these technical and vocational colleges. They developed an open systems theory of how organizations and organizational sub-units adapt to best meet the demands of their immediate environment and proposed that organizations must balance differentiation and integration to be successful. They found that a dynamic, unstable environment was associated with rather great "differentiation" or specialization of function in order to more effectively identify and respond to major environmental uncertainties (Herbert, 1977). According to Herbert (1977) great differentiation created needs for extensive coordination ("integration") of functional effort. Those companies who manage to achieve high sub-unit differentiation and yet still maintain high integration between sub-units seem to be best equipped to adapt to environmental changes. High differentiation and integration exists at the colleges as each department has to carry out its own educational functions but collaborate with other departments by providing cross-lecturing services. For example Lecturers from the Mathematics department provides lecturing services to the Computer department and Engineering department.

The Technical and vocational colleges' organizational design according to Wheeler and Hunger are all functional structure with wide spans of control that are tall and organic in structure thus maintaining a high manager-to-employee ratio, and that the tight supervision inherent in the mechanistic structure that is characteristic of bureaucracy is absent. A wide span of control exists because the heads for each schools or department supervises many lecturers and assistant lecturers. There is also the case where a matrix- like structure exists at the colleges because lecturers have to answer to more than one head of department, which at times causes confusion.

The organizational design may influence the stages of growth according to Weber. This is further supported in the works of Greiner. The Technical and vocational colleges are currently experiencing growth through coordination of the Greiner's phases of growth cycle; here projects and tasks are coordinated between all schools and departments so that they are well in place with each other. This is necessary as there are standard courses such as Mathematics and Communication studies that are taught throughout the colleges and departments work closely together where this is concerned. The coordination phase is also characterized by decentralized units; periodic review of planning procedures; initiation of college-wide programs is done by hiring staff; and the expenditures are also reviewed and distributed throughout the organization which oftentimes take a long time to be disbursed. There are instances where textbooks for the semester have been ordered but because of the bureaucratic redtape that exists, the Lecturers get those textbooks close to the end of the semester. 


\section{Miles and Snow Typology}

When the Miles and Snow typology was used to analyze the colleges and their educational environment, it was quite obvious that in general, they developed relatively unstable patterns of strategic behaviour in order to accomplish a good alignment with the perceived environmental conditions. The colleges are mere "Reactors" because the Deans and Heads of Schools frequently perceive change and uncertainty occurring in their departmental environments but are unable to respond effectively. This was evident during the rise of many offshore universities entering Jamaica as well as new universities existing locally. Because the colleges have a weak and inconsistent strategy-structure relationship, they did not make any adjustment to the quality and types of programmes offered until forced to do so by environmental pressures and competition.

The colleges need to continually search for market opportunities, regularly experiment with potential responses to emerging environmental trends, and become creators of change and uncertainty to which their competitors must respond, thus the institutions need to become "Prospectors".

\section{Issues of the institutions}

The technical and vocational colleges are faced with major issues as it relates to its structure and design as well as its culture. In this very dynamic, global and competitive educational environment, the colleges are in the process of re-positioning itself to meet the challenges that have been created with the information era. The task is great, but the colleges hope to succeed in its missions. Why is the structure of the colleges a complex one? This is because there are many structural problems associated with them such as:

- Differences in the system of operation and functioning

- Duality of roles: Heads of schools are also Deans of faculties

- Role conflict: Lecturers across departments and faculties reports to many coordinators, heads and assistant heads of schools

- Qualification and certification does not match the tasks to be carried out. Senior members of academic staff have various roles such as figureheads without the qualification to support positions and they are teaching courses out of their areas of competence.

- Lack of cohesiveness between members of staff

- High levels of negative workforce deviance

- Poor decision making within the organizations

- The structure of the institution and course designs lead to competition in the market. As such as soon as the students finish their Associate Degrees they move on to other universities and colleges without completing their first degree.

- Schools and programmes offered are moving with technology but at a slow pace.

- The organizational structures of the various technical and vocational colleges are constantly changing to reflect new positions and create more job categories that are not necessary for the scale and magnitude of the College's operations.

\section{Porter's five forces}

\section{PORTER'S FIVE FORCES AND SUSTAINED COMPETITIVE ADVANTAGE}

According to Porter a firm develops its business strategies in order to obtain competitive advantage over its rivals (Porter, 2008). This is done by responding to five primary forces: the threat of new entrants, rivalry among existing firms within an industry, the threat of substitute products or services, the bargaining power of suppliers, and the bargaining power of buyers (Ronquillo, 2012). 
Threat of new entrants: Puiu (2010) stated that new comers are companies that can compete or start companies already competing in an industry; bringing a desire to win and often have significant resources. However, new entrants to an industry brings new capacity and desire to gain market share that puts pressure on prices, costs and the rates of investment necessary to compete (Porter, 2008). Puiu (2010) further stated that new entrants enter the market when the profit margin is attractive and the barriers to entry are low.

Rivalry among existing firms: this is characterized by the intensity of competition in a particular industry to fill a specific market segment (Puiu, 2010). According to Porter (2008) rivalry is determined by factors such as price discounting, new product introduction, advertising campaigns, and service improvements.

Threat of substitute products or services: Porter (2008) states that a substitute performs the same or similar functions as an industry product by a different means; they are always present but tends to be overlook because they appear different from the industry's products. When the threat of substitutes is high, industry profitability suffers (Puiu, 2010).

Bargaining power of suppliers: This affects an industry when suppliers capture more of the value for themselves by charging higher prices, limiting quality or services, or shifting costs to industry participants (Porter, 2008).

Bargaining power of buyers: affect an industry through their ability to force lower prices, negotiate a better or more services and to determine competitors against each other (Wheelen \&Hunger, 2000). Porter (2008) further stated that buyers are powerful if they have negotiated leverage relative to industry participants, especially if they are price sensitive.

According to Ronquillo (2012) Porter's Five Competitive Forces Model has already been applied in a wide array of businesses including non-profit organizations where competitive advantage is a central theme, however, in this article it will be applied to the technical and vocational institutions.

\section{Level of competitiveness (Competitive advantage) versus Sustainable competitive advantage}

Barney (1991) stated that a firm is said to have competitive advantage when it is implementing a value creating strategy not simultaneously being implemented by any current or potential competitors. Ehmke (2008) extended the notion that competitive advantage is an advantage gained over competitors by offering customers greater value, either through lower prices or by providing additional benefits and service that justify similar, or possibly higher, prices. According to Porter (1985), competitive advantage for a firm is the result of complete comprehension of its external and internal environment. Porter (1985) further stated that "After it comprehends the market which it is activated in, its competitors, the wider exterior environment but also its strengths and weaknesses, it is possible later to discover its own unique core competencies and to be supported in one of the three types of competitive strategies - generic strategy - that is to say the leadership of cost, the strategy of differentiation and the strategy of focus".

Barney (1991) however stated that a firm has sustained competitive advantage when it is implementing a value creating strategy not simultaneously being implemented by any current or potential competitors, and when these other firms are unable to duplicate the benefit of this strategy. Organizations' success depends on employees' knowledge, experience, creative 
activity and qualification and emphasis is placed on continuous learning and research and development (Hana, 2013), these are some of the driving forces of sustained competitive advantage. This article tries to determine the level of competitiveness of the institution and whether it has achieved sustained competitive advantage using the Porter's five forces as predictors.

\section{METHODOLOGY}

A quantitative research design was used to analyze the effects of the Porter's five forces on the level of competitiveness of the technical and vocational institutions and whether or not they are able to maintain sustained competitive advantage.

\section{Research questions:}

1. Do the Porter's five forces determine the level of competition among the technical and vocational colleges?

2. Do the Porters five forces determine sustained competitive advantages among the technical and vocational colleges?

H1: There is a statistically significant relationship between threats to new entrants, threats to substitute products, suppliers bargaining power, buyers bargaining power, rivalry among competitors and the outcome variable level of competitiveness.

H 2: $\quad$ Threats to new entrants, threats to substitute products, suppliers bargaining power, buyers bargaining power, and rivalry among competitors are less likely to predict sustained competitive advantage.

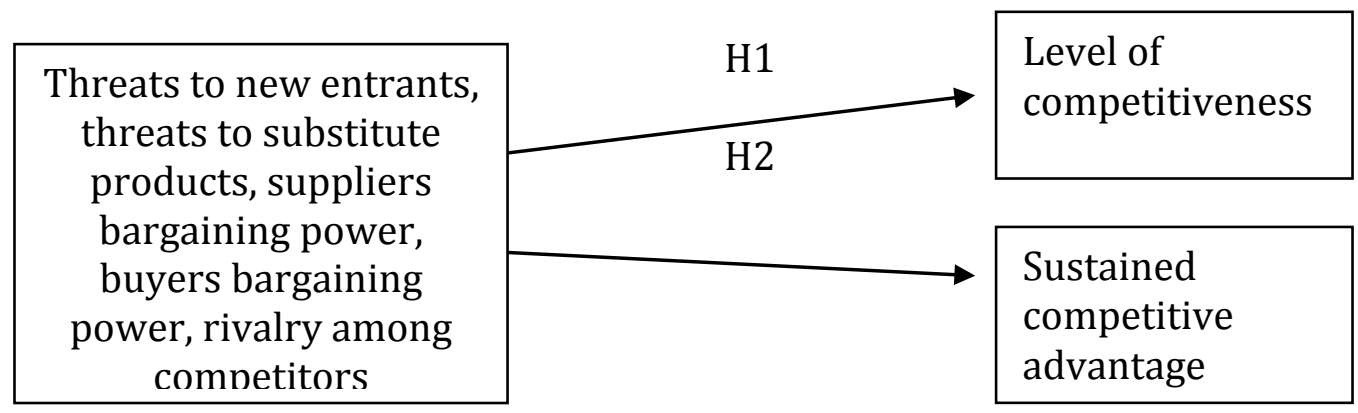

Figure 1: Theoretical Model

\section{Population and sampling}

A total of 100 respondents (20\% men and $80 \%$ women) between the ages of 18 and 50 were included in the sample of college staff employed to the two technical and vocational colleges under study of a population of 250 employees. The participants were selected by a purposive sampling method and reflected employees from different socioeconomic background and demographics within the technical and vocational institution.

\section{Instrumentation}

A questionnaire was developed consisting of three sections that captured information on the level of competition and sustained competitive advantage among the institutions as well as how the Porter's five forces impacted the institutions. Section one was developed to determine how Porter's five forces affected the level of competition among the technical and vocational 
colleges; section two was developed to determine whether the Porters five forces helped to maintain sustained competitive advantages of the institutions; while section three consists of a list of factors that affects organizational competitiveness which was derived using the Porter's five forces for which participants must rate the extent to which the factors affected competitiveness within their institutions.

\section{Data Analysis}

Descriptive statistics and frequency distributions were generated using SPSS 18.0 to describe the basic features of the data in the study and to check its accuracy. Correlation was used to determine the relationships between the Porters five forces and the level of competition among the technical and vocational colleges. Binary Logistic regression was used to determine the impact of multiple independent variables (threats to new entrants, threats to substitute products, suppliers bargaining power, buyers bargaining power, and rivalry among competitors) presented simultaneously to predict the outcome of sustained competitive advantage (the dependent variable category). Simple logistic regression analyses were conducted separately to estimate $\mathrm{p}$ value, odds ratios and their 95\% confidence intervals (C.I) for predicting the colleges' sustained competitive advantage.

\section{Measures}

Level of competition was determined by asking the respondents about the intensity of the level of competition experienced by the technical and vocational colleges on a scale of 1 to 5 , with 1 being "very low", 2 = "low", 3 = moderate, 4 = "high" and 5 = "very high". Sustained competitive advantage was determined by asking the respondents whether or not the technical and vocational colleges possessed value creating processes and positions that cannot be duplicated; while to determine threat to new entrants' respondents were asked if the colleges were greatly affected by the introduction of new universities and colleges in the educational market. Threats to suppliers bargaining power were determined by asking respondents if the suppliers of services were a source of power over the institutions. "Are the respondents placed under pressure by the customers who are sensitive to price changes?" and "Does the existence of substitute programs increase the likelihood of customers switching to alternative programs?" were two questions asked to determine whether or not there were threats to buyer bargaining power and threats to substitute products. To determine rivalry among competitors', respondents were asked if the technical and vocational colleges were exposed to intense rivalry among competitors.

\section{Data screening procedures}

Prior to data analysis, the data was screened for possible outliers, cases, and extreme values. It was also screened for normality (skewness and kurtosis) and homoscedasticity using plots and univariate descriptive statistics; and correcting problems in the data by the log or square root transformation methods.

\section{Coding and transformation of variables}

The variables chosen for this analysis relates to the institutions level of competition, sustained competitive advantage, threats to new entrants, threats to substitute products, suppliers bargaining power, buyers bargaining power, and rivalry among competitors in a sample of 100 (20 men and 80 women between the ages of 18 and 50 from two technical and vocational colleges in Jamaica. The outcome variable sustainable competitive advantage was coded 1 for the presence of sustained competitive advantage and 0 otherwise, while the independent variables threats to new entrants, threats to substitute products, suppliers bargaining power, buyers bargaining power, and rivalry among competitors were coded using dummy variables for the logistic regression analysis. 


\section{Descriptive statistics}

\section{RESULTS AND ANALYSIS}

A sample of 100 workers were analysed in this study with $20 \%$ being male and $80 \%$ females. Forty three (43\%) of these respondents held bachelor's degrees and twenty three (23\%) of which held postgraduate degrees in the areas of specialization they currently teach at the institutions. The remaining percentages represented workers who were facilitators and demonstrators holding qualifying certifications and associate degrees in respective technical and non-technical areas. Fifty Five (55\%) percent of the respondents were employed to the institutions for over ten years, $10 \%$ for over fifteen years and 10\% for over twenty years under the contract of services, while the remaining $25 \%$ being employed on a contractual basis and tenured for under ten years.

Table 1 show the means and standard deviations of the Porters five forces, with rivalry among competitors having the highest mean and standard deviation; pressures from key stakeholders was considered an important mix based on the prevailing situation of the institutions which had a mean of 3.23 and standard deviation of .898. Rivalry among competitors was considered important in the study (Table 2) as there were problems existed among the institutions relating to low customer loyalty, fierce competition among the technical and vocational institutions, and evidence of undifferentiated products and services.

Table 1: The means and standard deviations for the Porters five forces

\begin{tabular}{lcc}
\hline Porter's Five Forces & Means & Standard Deviations \\
\hline Threats to new entrants & 3.49 & .603 \\
Threats to substitute products & 3.51 & .517 \\
Suppliers bargaining power & 3.79 & .740 \\
Buyers bargaining power & 3.66 & .655 \\
Rivalry among competitors & 3.86 & .917 \\
*Pressure from key stakeholders & 3.23 & .898 \\
\hline
\end{tabular}

Table 2: The means and standard deviations for Rivalry among competitors

\begin{tabular}{lcc}
\hline Rivalry among competitors & Means & SD \\
\hline $\begin{array}{l}\text { There are many other universities and colleges } \\
\text { competing }\end{array}$ & 3.93 & .987 \\
$\begin{array}{l}\text { Products of the colleges are not differentiated and } \\
\text { can be easily substitutes }\end{array}$ & 3.32 & 1.294 \\
Competitors are of equal sizes & 4.05 & .757 \\
Colleges are competing against each other & 4.03 & .771 \\
Low customer loyalty & 3.96 & .777 \\
Average & 3.86 & .917 \\
\hline
\end{tabular}

\section{Correlation and Linear Regression}

Cohen and Cohen (1983) classified correlations as high, moderate, or weak according to unconnected $r$ values of $.50, .30$, and .10 , respectively, thus Table 3 shows high correlations between threats to substitute products $\left(\mathrm{r}=.733, \mathrm{r}^{2}=.537, \mathrm{p}<.01\right)$ and buyers bargaining power with the level of competitiveness $\left(r=.599, r^{2}=.358, p<.01\right)$. Threats to substitute products and pressures from key stakeholders were highly correlated with threats to new entrants $(\mathrm{r}=.530$, $\left.\mathrm{r}^{2}=.281, \mathrm{p}<.01, \mathrm{r}=.527, \mathrm{r}^{2}=.278, \mathrm{p}<.01\right)$, while suppliers bargaining power was highly correlated with pressures from key stakeholders $\left(r=.533, \mathrm{r}^{2}=.284, \mathrm{p}<.01\right)$. 
Table 3: Correlation among the Porters five force with the level of competitiveness

\begin{tabular}{|c|c|c|c|c|c|c|c|}
\hline & $\begin{array}{l}\text { Threats } \\
\text { to new } \\
\text { entrant } \\
\text { s }\end{array}$ & $\begin{array}{c}\text { Threats } \\
\text { to } \\
\text { substitut } \\
\mathrm{e} \\
\text { products }\end{array}$ & $\begin{array}{l}\text { Suppliers } \\
\text { bargainin } \\
\text { g power }\end{array}$ & $\begin{array}{l}\text { Buyers } \\
\text { bargainin } \\
\text { g power }\end{array}$ & $\begin{array}{c}\text { Rivalry } \\
\text { among } \\
\text { competitor } \\
\text { s }\end{array}$ & $\begin{array}{l}\text { *Pressure } \\
\text { from key } \\
\text { stakeholder } \\
\text { s }\end{array}$ & $\begin{array}{c}\text { Level of } \\
\text { Competitivenes } \\
\text { s }\end{array}$ \\
\hline $\begin{array}{l}\text { Threats to new } \\
\text { entrants }\end{array}$ & 1.00 & & & & & & \\
\hline $\begin{array}{l}\text { Threats to } \\
\text { substitute } \\
\text { products }\end{array}$ & $.530^{* *}$ & 1.00 & & & & & \\
\hline $\begin{array}{l}\text { Suppliers } \\
\text { bargaining } \\
\text { power }\end{array}$ & $.338^{* *}$ & $.222^{*}$ & 1.00 & & & & \\
\hline $\begin{array}{l}\text { Buyers } \\
\text { bargaining } \\
\text { power }\end{array}$ & $.400^{* *}$ & $.473^{* *}$ & $.200^{* *}$ & 1.00 & & & \\
\hline $\begin{array}{l}\text { Rivalry among } \\
\text { competitors }\end{array}$ & .142 & $.410^{* *}$ & .142 & -.066 & 1.00 & & \\
\hline $\begin{array}{l}\text { *Pressure from } \\
\text { key } \\
\text { stakeholders }\end{array}$ & $.527^{* *}$ & $.369^{* *}$ & $.533^{* *}$ & .066 & $.224^{*}$ & 1.00 & \\
\hline $\begin{array}{l}\text { Level of } \\
\text { competitivenes } \\
s\end{array}$ & $.255^{* *}$ & $.737^{* *}$ & -.018 & $.599 * *$ & $.353^{* *}$ & $.331^{* *}$ & 1.00 \\
\hline
\end{tabular}

Threats to new entrants, threats to substitute products, suppliers bargaining power, and buyers bargaining power were all statistically significant predictors of the level of competitiveness among the technical and vocational colleges. The five predictor model was able to account for $69.5 \%$ of the variation in the level of competition among the institutions, $\mathrm{F}(6,93)=38.59, \mathrm{p}<.05, \mathrm{R} 2=69.5 \% ; 30.5 \%$ of the variation in the level of competition among the institutions is explained by factors other than the Porters five forces.

Level of competition $=-.898+(-.066 *$ threat to new entrants $)+(.150 *$ threats to substitute products $)+(-.102 *$ Suppliers bargaining power $)+(.109 *$ Buyers bargaining power $)$.

Table 4: Predicting level of competitiveness from the Porter's five forces

\begin{tabular}{lccc}
\hline & B & SEB & $\boldsymbol{\beta}$ \\
\hline Constant & -.898 & .431 & \\
Threats to new entrants & -.066 & .015 & -.325 \\
Threats to substitute products & .150 & .019 & .629 \\
Suppliers bargaining power & -.102 & .020 & -.384 \\
$\begin{array}{l}\text { Buyers bargaining power } \\
\text { *Pressure from }\end{array}$ & .109 & .023 & .332 \\
stakeholders key & -078 & .015 & .407 \\
\hline
\end{tabular}

\section{Logistic regression}

A logistic regression analysis was conducted to predict the institutions sustained competitive advantage using threats to new entrants, threats to substitute products, suppliers bargaining power, buyers bargaining power, and rivalry among competitors as predictors. The omnibus test of the full model against a constant only model was statistically significant, indicating that the predictors as a set, reliably distinguished between the institutions that does and does not maintain sustained competitive advantage $\left(\chi^{2}(6)=5.504, p<.05\right)$; the Hosmer and Lemeshow 
test was non-significant and indicates that the model was a good fit; therefore we fail to reject the null hypothesis that there is no difference between observed and model predicted values. Nagelkerke's $\mathrm{R}^{2}$ of .075 indicated a weak relationship between prediction and grouping. Only $7.5 \%$ of the variation in the institutions sustained competitive advantage can be explained by threats to new entrants, threats to substitute products, suppliers bargaining power, buyers bargaining power, and rivalry among competitors, while $92.5 \%$ can be explained by other factors. Prediction success overall was $72 \%$ (as the model failed to correctly predict 28 cases) The Wald criterion demonstrated that only threats to suppliers bargaining power made significant contribution to prediction of sustained competitive advantage $(p<.05)$.

Predicted logit of (Sustained competitive advantage) $=1.312+(-.921) *$ threats to suppliers bargaining power

According to the model, the log of the odds of an institution maintaining sustained competitive advantage was negatively related to threats to suppliers bargaining power, ( $p<.05$; Table 3 ). EXP(B) value indicates that when suppliers bargaining power was increased the odds ratio was 0.398 times as small and therefore the technical and vocational colleges were .389 times less likely to maintain sustained competitive advantage, being $95 \%$ confident that the population value of the odds ratio lies between [CI]0.157 and 1.009. In other words, as the threats to suppliers bargaining power increase the less like it is that the institutions will maintain sustained competitive advantage.

Table 5: Logistics Regression Analysis of Reporting the impact of threats to new entrants, threats to substitute products, suppliers bargaining power, buyers bargaining power, rivalry among competitors and pressure from key stakeholders affecting sustainable competitive advantage.

95\% CI for Odds Ratio

\begin{tabular}{lllllc}
\hline Predictors & $\boldsymbol{\beta}$ & SE $\boldsymbol{\beta}$ & Lower & $\begin{array}{l}\text { Odds Ratio Upper } \\
\text { EXP (b) }\end{array}$ & \\
\hline $\begin{array}{l}\text { Constant } \\
\begin{array}{l}\text { Threats to suppliers } \\
\text { bargaining power }\end{array}\end{array}$ & 1.312 & 1.917 & & & \\
\hline
\end{tabular}

The Cronbach alpha reliability coefficient was $\alpha=0.89$ and fell within generally accepted limits.

\section{DISCUSSION}

\section{Applying Porter's Five Force Model to the Technical and vocational colleges of Jamaica}

Porter's theories were selected to analyze the colleges because they have "shaped a generation of academic research and business practice" (Harvard Business Review, 2008; Hua, 2011). When the Porter's model for industry analysis is used to analyze the prevailing situation, it is evident that the threat of substitute products, the threat of established rivals; the threat of new entrants; the bargaining power of the faculty and the bargaining power of students are very low for the technical and vocational colleges in comparison to the other universities and colleges in Jamaica.

The threat of substitute products: The cost of higher education is a significant factor for the colleges as the programme fees are lower in comparison to its major competitors for undergraduate technical and vocational education. However, one problem the institutions 
experiences is the inability to secure substantial scholarships, loans and grants each year to existing students and to attract enrolment. The Colleges threats to substitutes are high but they have to remain strategic in order to remain competitive. Many students are demanding alternatives that decrease the completion time for a degree or certification. Substitute products may come in the form of online and distance degree programmes which our technical and vocational colleges does not offer. It is clear that they have to put measures in place to retain the students, one such method could be through proper marketing, public relations and strategically aligning themselves to become more of a brand name instead of just a technical and vocational colleges and also to build a stronger alumni.

Rivalry among existing competitors: This takes many forms, including price discounting, new product introduction, advertising campaigns, and service improvements. In the education industry, the intensity of rivalry depends on the object of the competition: students, faculty, donors, or government-based funding and research dollars. For the technical and vocational colleges, new product introduction is slow even though there is a demand for those programmes. There has been a demand for the Associate Degrees in Environmental Science, Psychology and Banking and Finance but all the technical and vocational colleges have not yet reacted to those demands. With talks of introducing a logistic hub in Jamaica, only one of the two technical and vocational colleges has sought to capitalize on training in such area to keep up with its mandate.

The threat of new entrants: The colleges are faced with major competition from many universities, four year colleges and community colleges which have lowered their entry requirement standards. The presence of substitute business degrees can lower industry attractiveness and profitability because they limit price levels. This means that the colleges cannot overcharge students in terms of fees and service costs as customers will want to access cheaper technical and vocational education which gives the same or better recognition locally and internationally even if those degrees are not accredited with the University Council of Jamaica or National Council on Technical and Vocational Education and Training (NCTVET).

The power of the College as the supplier: The colleges have many support services such as bookstore franchises, health clinics, and food services, but many lack research facilities. Some department have the most qualifies lecturers holding master's and doctoral degrees who are less technically qualified, while other departments have more technical staff who are less structurally qualified; the colleges are weak structurally and are in need of development.

In applying the Porter's Competitive Strategy to the technical and vocational colleges it is clear that differentiation through branding, the physical aspects and the mode of delivery should provide a more sustained competitive advantage for the colleges competing for market leadership in the education industry. Branding the colleges will add value to each individual institution and offer more satisfaction for their consumers. However this is going to be a difficult task unless the structures of the individual colleges are changed or reengineered. In differentiating from its competitors, the college must include "quality", packaging, style, features and augmenting offers which are just some of the differentiation strategies.

\section{THE WAY FORWARD}

\section{Sustained competitive advantage}

Sustainable competitive advantages are required for educational institutions to thrive in today's global environment. Based on the application of theories above, the long awaited question may be asked - "Does technical and vocational colleges have sustainable competitive advantages?" When the institutions assets, attributes, or abilities are examined it is clear they 
are not difficult to duplicate or exceed. The technical and vocational colleges does not provide a superior or favorable long term position over their competitors, in fact they strive to be more like their competitors and not better than. The results obtained also showed that they are less likely to maintain sustained competitive advantage.

The way forward requires the colleges to strive to improve brand and customer loyalty, greater operational efficiency, focus more on skills training and technical vocational training, and greater employee productivity. There must be a stronger focus on product differentiation, employment of more qualified and competent staff, stronger management, greater transparency and a push for more research and publication among staff.

\section{A move towards a more efficient workplace through planned and radical changes}

Because of the many structural problems affecting the colleges and the increase in competition in the educational environment, there needs to be a change in the structure to a more feasible educational environment and one that will increase student intake and market share of the entity. According to Tsichritzis (1999) the university today must be redefined with new concepts: the internet allows virtual classrooms, digital libraries provide knowledge repositories, the Web offers up-to-date material for seminar discussions, and computer simulation substitutes for laboratories. What the Colleges need is to change its entire business process by reengineering its mode and delivery of tertiary education to allow for greater flexibility. According to Hammer and Champy (1993), Business Process Reengineering encompasses a radical thinking and redesigning of core organizational activities to achieve higher efficiency and performance (Clegg 2009). For this to happen the College's staff and students have to become intimate with technology and technological devices to move forward.

Transformational change is required for the College to succeed and move forward and requires a shift in assumptions made by the departments and its members. Lles and Sutherland (2003), states that transformation can result in an organisation that differs significantly in terms of structure, processes, culture and strategy. It may, therefore, result in the creation of an organisation that operates in developmental mode - one that continuously learns, adapts and improves (Iles and Sutherland 2001). When Lewin's force field analysis was applied to the current situation it is quite evident the some administrators are for and against the changes.

For business process reengineering to be successful, the Colleges need to stand on their own and sever ties with the Council of Technical and vocational colleges of Jamaica. The CCCJ have allowed for slow decision making, change management, and anomalies within the system. It drains the lecturers' capabilities and brain power through its constant requests for information and time that could have been put to better use.

All areas of the College must be reengineered from lesson delivery, to human resource management to the student administration system. Central to reengineering strategy is a determination to break out of the 'them and us' mould and to forge effective working relationships with faculties and departments (West, 1999). This is evident at the Colleges as there is a rift between academic and administrative staff, this is in need of change because all members of staff are working for one reason and that is to provide quality service to the students who are the customers.

\section{CONCLUSION}

There was a statistically significant difference between the Porter's five forces and the level of competitiveness among the colleges within the educational industry. The hypothesis holds 
true that Threats to new entrants, threats to substitute products, suppliers bargaining power, buyers bargaining power, and rivalry among competitors are less likely to predict sustainable competitive advantage. However, further research on how reengineering of the structure and function of the colleges to semi-virtual institutions may be studied to determine if impacts the level of competitiveness and sustained competitive advantage.

\section{Reference}

Barney, J., (1991). Firm Resources and Sustained Competitive Advantage. Journal of Management, Vol. 17 (1): 99 120.

Burns, T., Stalker, G.M., Mechanistic Organic Organizational Structure Contingency Theory.

Clegg. S., Kornberg. M., and Pitsis. T., (2001) Managing and Organizations: An Introduction to Theory and Practice. $2^{\text {nd }}$ Edition. pp. 528

Cohen, J. \& Cohen, P. (1983). Applied multiple regression/correlation analysis for the behavioral sciences. Hillsdale, NJ: Erlbaum.

Eckel, P., Hill, B. \&Green, M. (1998). On change: En route to transformation. Washington, D.C.: American Council on Education. An occasional paper series of the ACE project on leadership and institutional transformation, pp.85

Ehmke, C. Strategies for Competitive Advantage

Farmer, D.W. (1990). Strategies for change. In D.W. Steeples (Ed.), Managing change in higher education (pp. 7-1 8). New directions for higher education, Vol. 71. San Francisco: Jossey-Bass Publishers

Gallivan M. J. (2001), Striking a balance between trust and control in a virtual organization: A content analysis of open source software case studies, Info Systems J 11, 277-304.

Hana, U., (2013). Competitive Advantage Achievement through Innovation and Knowledge, Journal of Competitiveness, 5: 1, pp. 82-96, DOI: 10.7441/joc.2013.01.06

Herbert T. T., (1977), Is The Contingency Theory Of Organization a Technology-Bound Conceptualization? Journal of Management Volume 3, Number 1 pp 1 to 10

Lies and Sutherland, NCCSDO (2001) Managing Change in the NHS: Organizational Change. Available on line at www.sdo.lshtm.ac.uk (accessed November 2003), pp.13.

Porter, M. E., (2008). The Five Competitive Forces that Shapes Strategy. Leadership and Strategy, Harvard Business Review.

Porter, M. E. (1980). Competitive Strategy: Techniques for analyzing Industries and Competitors, New York: The Free Press.

Porter, M. E. (1985). Competitive Advantage. Creating and Sustaining Superior Performance, New York: The Free Press.

Puiu, S., (2010). The Model of the Five Competitive Forces on Romanian Retail Market. Annals of the University of Petroşani, Economics, 10(1): 289-298

Ronquillo, T., (2012). Analysis of Competitiveness of Batangas State University College of Engineering Using Porter's Five Competitive Forces Model. AAEE 2012 Conference Melbourne, Australia.

Schein, E., H. (1992), Organizational Culture and Leadership. San Francisco: Jossey-Bass Publishers, pp. 10

Thomas, H., Waxler, R. P., (1993), Corporate Cultures for the 1990's: What is needed? Corporate Environment January/February 1993, pp.356.

Tsichritzis D. (1999), Reengineering the University June 1999/Vol. 47 No 6 Communications of the ACM, pp.94 97.

Torraco R. J. (2005), Work Design Theory: A Review and Critique with Implications for Human Resource Development. Human Resource Development Quarterly, vol. 16, no. 1,Wiley Periodicals, Inc, pp.90 
West A. (1999), 'Re-engineering' student administration - a practical case-study PERSPECTIVES, Volume 3, Number 3, Autumn1999, pp.115.

Wheelen, T.L \& Hunger, J. D. (2000) Strategic Management and Business Policy - Entering 21st Century Global Society, 7-th edition, Prentice-Hall, New Jersey

Wilms, W. W. (1996). Restoring prosperity: how workers and managers are forging a new culture of cooperation. New York: Times Books, pp.81

Zaridis, A., D., (2009) Competitive Advantage and its Sources in an Evolving Market. Computational Method in Science and Engineering, Advances in Computational Science Vol. 2. 